\title{
Role of Information and Communication Technology in Motivating University Undergraduate Students towards a Learning Task in Public Sector Universities of Rawalpindi City
}

\author{
Author's Details: \\ ${ }^{(1)}$ Zarqa Farooq Hashmi ${ }^{(2)}$ Dr. Muhammad Arshad Dahar ${ }^{(3)}$ Azhar sharif \\ ${ }^{1}$ M.Phil. Student department of education, (PMAS-AAUR). ${ }^{2}$ Supervisor ${ }^{3}$ M.Phil. Scholar, Research and training \\ officer
}

\begin{abstract}
:
Over the past few years, information and communication technology has become constantly used in the education especially in the schools, colleges and universities. At the age of globalization technology has its impact upon almost all aspects of life. The purpose of this paper is to explore the role of information and communication technology (ICT) in the motivating University students. The main objectives of the study were to assess motivational features of information and communication technologies as perceived by students. The independent variable of the study was ICT and dependent variable was student's motivation. Questionnaire was used in the study to collect data. The type of research was survey descriptive research. The sample size of 340 undergraduate students was selected through simple random sampling. Descriptive statistics mean, standard deviation, frequency and percentage were used in the study. Inferential statistics i.e., chi square test was employed for statistical analysis of the data through SPSS. The findings of the study show that ICT effects students' motivation and improves their learning; knowledge retention and understanding. ICT can solve the problems of the students and motivates students
\end{abstract}

\section{Key Words: ICT, Motivation, Motivational features of ICT,}

\section{Background of the study}

ICT is turning into a changing operator in the present world. It can change the lives of people groups. All around the globe individuals are utilizing ICTs as a wellspring of learning and data. It is utilized now daily in the relatively every field of the existence business, wellbeing and education. ICTs like social Medias and different learning destinations can undoubtedly provide a great deal of knowledge. ICT enhances the comprehension of the lesson. It is accounted in the Organization of Eastern Caribbean States [OECS] (2002) that ICTs majorly affect the all parts of society. There are just a few everyday issues, at home, at school and at work, where this new innovation has no impact. ICT grows our openness and comprehension of the world. The World Economic Forum (2009) expressed the utilization of ICTs to be extremely poor in Pakistan. This must be an intense concern. This idea has turned into the wellspring of inspiration for the investigation. It is viewed as that ICT for elderly individuals will take cares the major issues of the people groups. ICT can address the needs of the individuals. If ICTs must be integrated into the studies then students are more motivated towards the learning. ICTs can address the needs of students and make them active members.

\section{INTRODUCTION}

The role of technology has enlarged quickly in recent years. Peoples from all sectors like economic sectors, educational sector are taking advantage from the ICTs. The term "information technology" is discovered in the 1970s but this term is used for the first time in the World War II for the military training purpose. In World War II military felt the need of the communication technology to communicate with each other's.

The ICT is an arrangement of specialized gadgets and apparatuses used to share thoughts and data between the general populations. It can likewise be utilized to store, process and arrange data. This extensive meaning of ICT contains a wide range of technology like recordings, DVDs, telephones, satellite, radio, TV, PCs, equipment and programming systems, innovation, equipment, specialized administrations and technical services.

Technology has become an incredible asset in every area of our lives (from education, work, and entertainment in personal life). ICT has become one of the core and core components of our society today.ICT and students learning and motivation have no direct effect. ICT enables peoples to communicate with each other. If ICT must be integrated into the learning then students are more motivated and take more interest in the learning.

Motivation is a key element of the learning. If students are motivated towards a task then commitment to the learning task, enjoyment and self-esteem increase. Creative and new technologies have helped to increase student participation and encourage teachers. It also increases students as well as teacher's motivation resulting in changed relationships among teachers and students with the knowledge. 


\section{OBJECTIVES OF THE STUDY}

The main objectives of the study are as given below.

1. To assess motivational features of information and communication tools as perceived by students.

\section{RESEARCH QUESTION}

1. What are the motivational features of the ICTs?

\section{Concept of ICT}

From the previous couple of years ICTs are regularly giving communication services. Individuals can speak with each other's through technologies. ICT used to send and get messages. This innovation incorporates Skype, face book, What Sapp, texting, video-conferencing. Information communication locales Like Gmail, hotmail, face book and twitter enable clients to keep in contact and share thoughts. Present day ICT has made the world a "global village". Peoples can speak with each other from distance through ICTs. The main idea of ICT is a combination of apparatuses and gadgets and different instruments which are used for performing and handling particular tasks. These tasks incorporate the publication of articles, save of the course and convey of content, correspondence, preparing and sharing of information. Components of ICT devices and tools are used to gather data and store information. ICT is an expansive term. Every one of the things utilized for the communication is incorporated into the ICTs.

The basic term means "information" means any reality or connection to the asset. It includes details about reality, data or opinion in any medium, relative, digital, graphic, narrative or audio form. "Communication" is the process of sharing of information between two peoples or within two peoples. The term 'ICT' is characterized as "forms of technology utilize for creating, displaying, making, controlling, storing, manipulating, and exchanging data or information". ICT specifically refers to computer-based technologies. This includes tablets, desktops, workstations, laptops, smart phones, and programming and web-based innovations. This includes emails, person to person communications destinations, and social networking sites.

There are some definitions of ICT in educational environments for learning and teaching. UNESCO (2002) defines ICT as "forms of technology that are used to transmit, process, store, create, display, share or exchange information by electronic means." Christenson (2010) defines ICT as "technologies that provide access to information through telecommunications. It is similar to information technology (IT) which includes the Internet, wireless networks, cell phones, and other communication mediums".

\section{Importance of ICT}

These technologies are used to carry out a large range of communication and information functions. It has many benefits for the peoples. People can easily contact with one another through these technologies. It can provide communication, information, employment services. It can also provide electronic commerce, independent living, intergenerational relationship, distance learning services. These services can minimize human work and provides ease of access. It can also provide cost reduction and strengthening the community services.

ICTs provide universal access to education. ICT can provide anytime and anywhere learning facilities to the learners. Different type of websites provides online learning material which can be accessible 24 hours. Teleconferencing is a latest learning technique. It allows both learners sand teachers to interact at the same time with ease and convenience ICT can change the whole teaching and learning process. It can make classroom an active learning atmosphere and learners as an active learner. ICT has become popular concept because of the facilities it provides to learners. It changed the whole philosophy of education. It distorted the function of teacher from an energetic tutor to an active catalyst.

Following is the importance of the ICT in the students learning.

1. Provide access to large quantity of learning resources.

2. Quick access to information.

3. By the use of ICTs learning can occurs anytime.

4. By the use of ICTs learning can occurs anywhere.

5. Collaborative learning takes place if ICTs is merged into the education. 
6. Gives multimedia approach to education

7. Provide valid and up to date information

8. Provide access to online libraries

9. teaching of different subjects made interesting

10. Gives opportunities for the instructive data storage

11. Provides the facility of distance education

12. Provides access to the wide source of information.

\section{Motivation}

Through motivation interest is increased and hidden goals are achieved. Motivation is derived from the Latin word mover which means to move. Motivation is an external force which accelerates a response or behavior. Motivation is generally defined as an inside situation that initiates performance. Motivation develops interest and makes learning fun. Motivation creates the want to achieve a goal. Motivation is the key to academic success. It promotes lifelong learning. Motivation is an essential criterion that is required when engaging in a task. It is a factor that stirs up and guides performance. Sanacore 2008 states that Motivation is the key to academic success as well as promoting lifelong learning. ICT have many motivational features it develops interest, curiosity, confidence improves thinking and reasoning skills of the students.

Motivation is the desire to do things, and the drive towards a goal. It includes external and internal factors to keep people consistently interested and committed to a task, responsibility or subject, or to put effort to achieve an objective. Motivation is a fundamental ingredient in setting and achieving goals. An individual's level of motivation can be influenced by himself and by others. Motivation influences which consequences are reinforcing and which ones are punishing. The more a student is motivated to succeed, the more he is excited for a higher grade and distressed by a dismal performance. Motivation often boosts performance. Learners who are often motivated to participate in classroom discussion and activities tend to be higher achievers.

Motivation enhances initiation and determination in activities. People who are motivated are likely to start a task and pursue it to the end. Employees who are not motivated skip meetings and training workshops and may not perform to their best in their responsibilities. Motivation is usually described as an internal condition that starts to perform or initiates a behavior or conduct. It Promotes interest and generate intense pleasure. The motivation creates the desire to achieve the goal. It is the key of success in education. It promotes rapid learning. Motivation is a basic standard that initiate needs to be involved in work. It is an element that guides performance and guides individuals.

\section{TYPES OF MOTIVATION}

Motivation can be both extrinsic and intrinsic. People may be motivated by factors in the external environment such as pay, benefits and job perks. Factors can be influenced by people like external environment such as wages, benefits, and active stability. This is called as an external drive or external motivation. It can be inspired by the relationship between worker and work. Such motives call themselves motivation. These factors often occur at the same time, but we will isolate them because they have a specific level of encouragement.

\section{Extrinsic motivation}

Extrinsic motivation is related to 'tangible' rewards such as fringe benefits, security, promotion and condition of work. Extrinsic motivation is often necessary for persistence of motivated behavior.

\section{Intrinsic motivation}

Intrinsic motivations are the self-generated factors which influence people to behave in a particular way or to move in a particular direction. Intrinsic motivation arises from having "a strong emotional interest in an activity and a sense of freedom and autonomy related to it"

\section{ROLE OF ICT IN THE STUDENTS MOTIVATION}

ICT and student's motivation have no direct effect. ICT enables people to communicate with each other. ICT can provide anytime and anywhere learning facility. If students are motivated towards a task then commitment, enjoyment, learning and self-efficacy increase. ICT ensures the creation, support, development and development of a knowledge society. This society leads to the all-round socio- economic development of the nation.

ICT is the key of learning. It provides following advantages. 


\section{ICT develops Interest}

The ability of forms of ICT to capture pupil interest is clear. However, interest can be defined in two different ways:

- Situational interest: in which elements of the situation grab the interest of participants. To some degree, the interest remains dependent upon the continuing situational influence.

- Personal interest: in which a disposition on the part of the individual to pursue the activity in question is assumed. Situational interest is more likely to develop into personal interest under situations where relatively high levels of personal control are able to develop. The key here is to disentangle any effects of ICT in creating situational interest from those that enable the development of personal interest. In the context of the measures employed in this study, the best conditions for the development of personal interest will be obtained when intrinsic motivation, identified regulation and learning goals are all relatively high.

\section{ICT develops Concentration in lesson}

Concentration is the key of the success. ICT develops concentration among the learners. As compared to a normal lesson a lesson delivered through ICT is more interesting for the students. ICT provides more motivation to the learners. It improves critical thinking skills of students.

\section{ICT improves Commitment to a task}

Becker 2000 stated that Commitment is important for the successful completion of a task. ICT improves learner's commitment to a task. When ICTs are used then students take more interest in the learning thus their commitment to the task also increases. Students are generally more 'on task' and express more positive feelings when they use computers than when they are given other tasks to do.

\section{ICT provides Enjoyment}

Enjoyment is important for the step in the learning process. ICT gives enjoyment to the learners and makes learning fun. When ICTs are used then student at a time can visualize things and listen voice also. So, they enjoy learning because all their senses are activated at a time.

\section{ICT Encourage students}

Encouragement means to push or to give confidence. Encouragement is important for the learning. ICT encourages learners and improves motivation. ICT encourages students to understand multiple aspects of a topic. It gives productive knowledge to the learners. ICT motivates learners and provides them better understanding.

\section{ICT Develops connection to the real-life problems}

By using ICT students can practice things by doing thus it develops a connection with the real-life problem. ICT develops learning by doing attitude among the learners. ICT allow learners to explore and discover things rather than merely listen and remember. It improves knowledge and understanding and develops a connection with the real life.

\section{ICT Develops curiosity among the students}

Curiosity means to develop passion to complete a task. ICT develops curiosity among the learners. Students can practically perform a task by using ICTs so they are active members and their curiosity in a learning task also improves.

\section{ICT Enhances thinking and reasoning skills of the students}

ICT enhances the thinking and reasoning skills of the students and improves critical learning skills of the students. By using ICTs student can understand the multiple aspects of content. ICT allows students to reflect on a topic.

\section{ICT Makes things easier}

ICT makes learning fun for the students and improves the memorization ability of the students. Students can easily pick up a task and easily perform it. It's easy for the students to learn things.

\section{ICT clears better concepts of the students}


Software and information Industry Association 2000 stated that Students, who used educational technology in school felt more successful in school, were more motivated to learn and have increased self-confidence and selfesteem. CT can minimize the communication gapes and thus clears the better concepts of students.

\section{ICT provides knowledge Retention}

Miller, 2009 stated that Students of the 21st century may retain more information if it comes to them through a digital medium. ICT helps students in knowledge retention. Students can easily remember a lot of information without any difficulty.

\section{LITERATURE REVIEW}

Volman, 2005 indicates that Schools in the Western World invest a lot for ICT infrastructures from the last 20 years. In these countries students often use computers for a much larger range of applications. Western institution gives important to the ICT facilities. In Pakistan ICTs are not used frequently in the school, colleges and universities. The ICT resource and facilities are not present in the adequate amount in the institutions.

Kok, 2007 states that ICTs is increasingly permeated in every aspect of life because ICTs are excellent tools for information processing, the new generation needs to become competent in their use, should acquire the necessary skills, and therefore must have access to computers and networks. ICT facilitates new and innovative skills. It provides access to the countless new resources.ICT provides anytime and anywhere learning facilities. ICT has the potentials to enrich, motivate, encourage and strengthen student's skills and knowledge.

Oyzon \& Olmos (2010) pointed out learning motivation as an intrinsic process to induce students' learning activities, maintain the learning activities, and have the learning activities move towards the objectives set by teachers so as to achieve instructional objectives and proceed effective instruction.

According to Heemskerk, Volman, Admiraal and ten Dam (2011), "Information and communication technology (ICT) in education is assumed to contribute to educational equality due to its motivating effects on students and the opportunities it offers for facilitating differentiation and individualization". ICT is considered as a main source of knowledge and learning as it allows the storage and retrieval of information and provides universal access to knowledge.

Crook, 2011 has been proved that ICT is a valuable gift in life-long and distance learning, simply because it provides an effective delivery vehicle for course content where learners participate and work in a form of collaboration community. ICT provides virtual learning, e-learning and different learning software's to the students.

Porter et al. (2012) considered that learning motivation could guide individual learning objectives as well as induce the sustainable learning behaviors, reinforce the cognition process, and strengthen and improve the learning outcomes (Marijana,2015).

Şahbaz (2012) regarded learning motivation as the intention or desire of students participating and devoting to learning, which was performed on students' selection for specific learning activities and the strength to continuously devote to such activities. Consequently, learning motivation is defined in this study as being able to guide students to sustainable learning and make efforts to the learning objectives set by teachers, in the learning activity process.

Referring to Baş's (2012) Expectancy Value Model, motivation contains work value, expectancy for success, and ability beliefs in this study. 1. Work value refers to students' evaluation of the learning. 2. Ability beliefs refer to students perceiving the ability in the learning. 3. Expectancy for success refers to students' expectation about the future learning performance.

Kukkonen et al. (2013) defined motivation as extrinsic behaviors and intrinsic learning motivation of an individual. Cindy \& Douglas (2010) regarded motivation as the essential condition for long-term, effective, and meaningful learning. Learning motivation was a kind of motivation.

Finally, Kirkwood (2014) claims that the adoption of technology helps students in constructive learning and knowledge building as technologies can create a context-free environment. ICT can improves the students learning skills as it can provide learning by doing facilities. Students can practice things so better concepts are cleared. 
Yoloye, 2015 told that the application of ICTs has already changed the organization and delivery of higher education. ICT changes the student's role from the passive learners to active learners. It can change the whole philosophy of education. Students can easily gain knowledge through different learning sites anytime from anywhere.

\section{RESEARCH METHODOLOGY}

\section{Population}

This study aimed to investigate the role of ICT in the motivation and learning of the University students. The targeted population of the study is all the University students who are using ICT in their learning. The accessible population consists of the students of the 4 universities of district Rawalpindi. So, total population of the study is the 34076 undergraduate students from the six department's economics, political sciences, IR, mass communication, psychology and Pakistan studies of four Universities PMAS Arid-Agriculture, NUML, ISLAMIC and QUAID-E-AZAM.

\section{Sample and Sampling Technique}

Sample is the sub group of the population from which researcher generalize their study. Through L.R Gay method sample must be collected.7\% of population must be taken by taking help from the L.R Gay table.340 is the sample size. Undergraduate students must be taken. 4 universities must be taken to collect final data PMAS-AAUR, NUML, ISLAMIC and Quaid-e-Azam.

\section{Research Design and Instrument}

Quantitative techniques were used in this research. A self-developed questionnaire was used to find out the role of Information and Communication Technology in the motivation. The questionnaire was developed by researcher with the help of supervisor. After pilot study, reliability of the questionnaire was determined. Again it was checked by two experts for its finalization for pilot testing.

\section{Pilot Testing, Validity and Reliability}

The aims of pre-testing were to assess that whether the questionnaire built for study is easily understood by the respondents are not and to assess the technical functioning of the questionnaire. 2 Universities Federal Urdu University and Fatima Jinnah Woman University must be taken for the purpose of pilot testing.30 questionnaires must be filled from the students randomly. After obtaining results from pretesting the original questionnaire and interview was finalized with the help of Supervisor and necessary amendments were made. Validity of the instrument was essential in the study as it certifies that inferences established on the collected data were precise and meaningful (Mugenda and Mugenda,2003). Validity of the instrument is measured through experts.3 experts can check the validity of the questionnaire after that questionnaire is finalized. Reliability is the degree to which a research gives same results when it is conducted after some time. Reliability of the questionnaire is measured through the SPSS. Research Instruments Reliabilities which contained No of item were selected and value of Cron bach alpha is measured.0.753 is the cron bach alpha value.

\section{DATA COLLECTION AND ANALYSIS}

Data collection process was commenced on 15 February 2018 and completed on 15 March 2018. The researchers personally visited the target sample. Before the distributing of questionnaires, purpose of the study was explained to the respondents and they were asked to respond freely without any hesitation. Then questionnaires were delivered to respondents and $100 \%$ response rate was achieved due to follow up study. Raw data was collected, classified, tabulated, analyzed and interpreted through descriptive statistics i.e., mean, standard deviation.

\section{RESULTS}

The study was descriptive and quantitative that was planned to investigate the role of information and communication technology in the motivation of the University students in the Public universities of Rawalpindi city. Self-developed structured questionnaires were used for gathering information from the respondents. After collection of data, it was properly organized, classified, tabulated and analysis through descriptive statistics i.e., mean, standard deviation.

Table 4.1: Gender of Respondents

\begin{tabular}{|l|l|l|l|}
\hline S.No & Gender & Frequency & Percent \\
\hline 1 & Male & 170 & 50 \\
\hline 2 & Female & 170 & 50 \\
\hline & Total & 340 & 100 \\
\hline
\end{tabular}


From the above frequency table, it was getting informed that the total number of respondents which selected as a usable sample was 340. From this sample size, the 170 numbers of respondents were male and 170 were female. The total percentage is $50 \%$ and $50 \%$ of males and females respectively.

\begin{tabular}{|c|c|c|c|c|c|}
\hline Sr. \# & Statement & $\mathrm{X}^{2}$ cal & D.f & Sig. Value & $X^{2}$ tab \\
\hline 1 & ICT makes course more interesting and lively. & 563.353 & 4 & .000 & 9.49 \\
\hline 2 & $\begin{array}{l}\text { ICT helps student to complete a piece of work that sometimes would be } \\
\text { difficult to complete without it. }\end{array}$ & 320.447 & 4 & .000 & 9.49 \\
\hline 3 & Students pay more attention when lessons involve the use of ICT. & 413.576 & 4 & .000 & 9.49 \\
\hline 4 & Using ICT makes topics visually attractive. & 721.912 & 4 & .000 & 9.49 \\
\hline 5 & By using ICTs student can work longer without losing concentration. & 416.088 & 4 & .000 & 9.49 \\
\hline
\end{tabular}

The statement No 1 ICT makes course more interesting and lively calculated chi-square value is 563.353 at 0.000 level of significance. Degree of freedom is 4 . Tabulated chi-square value is 9.49 at the 0.05 level of significance. The measured value is greater than tabulated value hence, the statement is accepted.

The statement No 2 ICT helps student to complete a piece of work that sometimes would be difficult to complete without it calculated chi-square value is 320.447 at 0.000 level of significance, degree of freedom 4 is greater than the tabulated chi-square value is 9.49 at 0.05 level of significance; the measured value is greater than tabulated value hence, the statement is accepted.

The statement No 3 Students pay more attention when lessons involve the use of ICT calculated chi-square value is 413.576 at 0.000 level of significance, degree of freedom 4 is greater than the Tabulated chi-square value of 9.49 at 0.05 level of significance; The measured value is greater than tabulated value hence, the statement is accepted.

The statement No 4 Using ICT makes topics visually attractive calculated chi-square value is 721.912 at 0.000 level of significance, degree of freedom 4 is greater than the Tabulated chi-square value of 9.49 at 0.05 level of significance; the measured value is greater than tabulated value hence, the statement is accepted.

The statement No 5 By using ICTs student can work longer without losing concentration calculated chi-square value is 416.088 at 0.000 level of significance, degree of freedom 4 is greater than the Tabulated chi-square value of 9.49 at 0.05 level of significance; The measured value is greater than tabulated value hence, the statement is accepted.

\begin{tabular}{|c|c|c|c|c|c|}
\hline Sr. \# & Statement & $X^{2}$ cal & D.f & $\begin{array}{c}\text { Sig. } \\
\text { Value }\end{array}$ & $X^{2}$ tab \\
\hline 1 & Working with ICT is a fun for the students. & 444.324 & 4 & .000 & 9.49 \\
\hline 2 & ICT helps students to explore learning resources. & 426.000 & 4 & .000 & 9.49 \\
\hline 3 & ICT is helpful in motivating students. & 692.971 & 4 & .000 & 9.49 \\
\hline 4 & ICT can enhance student's participation and feedback to teachers. & 463.706 & 4 & .000 & 9.49 \\
\hline 5 & ICT help to generate a pleasant atmosphere in the classroom. & 505.118 & 4 & .000 & 9.49 \\
\hline
\end{tabular}

The statement No 1 Working with ICT is a fun for the student's calculated chi-square value is 444.324 at 0.000 level of significance, degree of freedom 4 is greater than the Tabulated chi-square value of 5.991 at 0.05 level of significance; tabulated value is smaller than the calculated value hence, the statement is accepted.

The statement No 2 ICT helps students to explore learning resources calculated chi-square value is 426.000 at 0.000 level of significance, degree of freedom 4 is greater than the Tabulated chi-square value of 5.991 at 0.05 level of significance; the measured value is greater than tabulated value The measured value is greater than tabulated value hence, the statement is accepted.

The statement No 3 ICT is helpful in motivating students calculated chi-square value is 692.971 at 0.000 level of significance, degree of freedom 4 is greater than the Tabulated chi-square value of 5.991 at 0.05 level of significance; The measured value is greater than tabulated value hence, the statement is accepted.

The statement No 4 ICT can enhance student's participation and feedback to teachers calculated chi-square value is 463.706 at 0.000 level of significance, degree of freedom 4 is greater than the Tabulated chi-square value of 5.991 at 0.05 level of significance; The measured value is greater than tabulated value hence, the statement is accepted.

The statement No 5ICT help to generate a pleasant atmosphere in the classroom calculated chi-square value is 505.118 at 0.000 level of significance, degree of freedom 4 is greater than the Tabulated chi-square value of 5.991 at 0.05 level of significance; The measured value is greater than tabulated value hence, the statement is accepted. 


\begin{tabular}{|c|c|c|c|c|c|}
\hline Sr. \# & Statement & $\mathrm{X}^{2}$ cal & D.f & Sig. Value & $\mathbf{X}^{2}$ tab \\
\hline 1 & The use of ICT improves student's grades. & 695.735 & 4 & .000 & 9.49 \\
\hline 2 & The use of ICT enhances quality of education. & 330.000 & 4 & .000 & 9.49 \\
\hline 3 & ICT provides students freedom of expression. & 711.265 & 4 & .000 & 9.49 \\
\hline 4 & The use of ICT develops more interest among the students. & 482.912 & 4 & .000 & 9.49 \\
\hline 5 & $\begin{array}{l}\text { ICT provides quick and easy access to materials needed by } \\
\text { students. }\end{array}$ & 513.265 & 4 & .000 & 9.49 \\
\hline
\end{tabular}

The statement No 1 The use of ICT improves student's grades calculated chi-square value is 695.735 at 0.000 level of significance, degree of freedom 4 is greater than the Tabulated chi-square value of 5.991 at 0.05 level of significance; The measured value is greater than tabulated value hence, the statement is accepted.

The statement No 2 The use of ICT enhances quality of education calculated chi-square value is 330.00 at 0.000 level of significance, degree of freedom 4 is greater than the Tabulated chi-square value of 5.991 at 0.05 level of significance; The measured value is greater than tabulated value hence, the statement is accepted.

The statement No 3 ICT provides students freedom of expression calculated chi-square value is 711.265 at 0.000 level of significance, degree of freedom 4 is greater than the Tabulated chi-square value of 5.991 at 0.05 level of significance; The measured value is greater than tabulated value hence, the statement is accepted.

The statement No 4 The use of ICT develops more interest among the students calculated chi-square value is 482.912 at 0.000 level of significance, degree of freedom 4 is greater than the Tabulated chi-square value of 5.991 at 0.05 level of significance; The measured value is greater than tabulated value hence, the statement is accepted.

The statement No5 ICT provides quick and easy access to materials needed by students calculated chi-square value is 513.265 at 0.000 level of significance, degree of freedom 4 is greater than the Tabulated chi-square value of 5.991 at 0.05 level of significance; The measured value is greater than tabulated value hence, the statement is accepted.

\section{DISCUSSIONS}

The present research is based on the role of ICT in the motivation of the students. A self-develop questionnaire was used for gathering the information from the respondents. ICT and related technologies enhance student's participation and feedback and according to student's point of view these are helpful for them. Swan et al. (2005) reported that student feel using mobile devices makes learning fun and made schoolwork interesting. This study supports my current study. Technology improves motivation, engagement and interest. It develops more understanding of the subject.

Kok 2007 conducted study on topic "Impact of ICT on the teaching and learning" also supports current study. ICTs is became increasingly used in every aspect of life (work, learning, leisure, and health). ICTs are excellent tools for information processing. There is a need that new generation must have knowledge of the ICTs and related technologies. It was concluded through present research that the use of technology improves student's interest and learning.

Nazu Shauke nova 2016 stated that ICTs are helpful for the students so it must be used in the studies. Most of the people say that technology must be used in the learning process because learning improves by the use of technology. We are living in the know ledged society. Communication can be done easily in the present society. Learning must be fun and teacher must be facilitator. Students can easily take help from social Medias and different types of learning software's are also present. People take help from them. Complex tasks can be easily done through this. Students who are taught through ICTs and related technology are more motivated and they take more interest in the learning process as compare to the students who are not taught through the ICTs. Most of the peoples have access to the modern technology and they think that ICTs and modern technology is essential for their future.

\section{CONCLUSION}

The major conclusion of this research is that usage of ICT is very essential to improve the educational efficiency of students. Results show that ICT can helpful to produce the productive knowledge of students related to their studies. Findings suggest that more the usage of ICT in education sector will increase the results and efficiency of students. Students were agreeing that ICT provides vast knowledge to students through internet and digital libraries, so it can helpful to enhance the educational efficiency at local, regional and national level. After analyzing all the results, we conclude that ICT brings a positive impact on the Public-sector Universities of Pakistan. 


\section{RECOMMENDATIONS}

1. Reasonably skilled persons may be hired. Monetary and technical support should be provided to universities.

2. Computer labs should be updated. E-based assignments should be preferred instead of paper-based assignments.

3. Do it yourself attitude should be developed among the learners. Master teachers may be trained for applying ICTs. Course contents should be redesigned to acquire more benefits from ICTs. At least one computer with internet access and an LCD projector should be provided in every class.

4. More ICT-related courses should be offered for teachers and learners. Every ICT-related course should be practice-oriented.

\section{REFERENCES}

i. Baş, G. (2012). Reading attitudes of high school students: an analysis from different variables. International Journal on New Trends in Education and Their implications, 3(2),47-58.

ii. BECKER, H., 2000. Pedagogical motivations for pupil computer use that lead to student engagement. Educational Technology, 40 (5), pp.5-17.

iii. Christensson, P. (2010, January 4). ICT Definition. Retrieved 2016, Dec 28, from http://techterms.com

iv. Crook, C. (2011). Versions of computer supported collaborating in higher education. Learning across sites: New tools, infrastructures and practices, 156-171.

v. DR. JOHNESTER ALI MWANGULU, The Role of Technology as a Key Driver to Smes Competitiveness $-A$ Case of Smes in Nairobi County, International Journal of Management Sciences and Business Research 11(2017):131-136

vi. Elahe Hosseini, Amirmohammad Nabaei, Fatemeh hajian, Negin Hamidpour, Investigating the Culture Impact on Organizational Resilience in Organizational Enterprise area (A Case Study of Iran's Ministry of Communication and Technology), International Journal of Management Sciences and Business Research 12(2017):27-35

vii. Ernest Kipkemei, Analysis of Socio-economic Factors Influencing the Adoption of Breeding Technologies among Dairy Farmers in the North Rift Region of Kenya, International Journal of Management Sciences and Business Research 12(2017):143-168

viii. Fahad Ali Alqammash, The role of trust in consumer acceptance of E-Commerce in Saudi Arabia, International Journal of Management Sciences and Business Research 11(2017):10-16

ix. Heemskerk, I., Volman, M., Admiraal, W., \& ten Dam, G. (2012). Inclusiveness of ICT in secondary education: students' appreciation of ICT tools. International Journal of Inclusive Education, 16(2), 155170.

x. Hasnain Javed, Cai Li, Saba Fazal Firdousi, Muhammad Abdul Wahid Zafar, The Mushrooming Impact of Technology Business Incubators on Economic Development: A Case Study from Kingdom Of Saudia Arabia, International Journal of Management Sciences and Business Research 01(2018):69-83

xi. Jung, I. (2005). ICT-Pedagogy Integration in Teacher Training: Application Cases Worldwide. Educational Technology \& Society, 8 (2), 94-101.

xii. Kirkwood, A. (2014). Teaching and learning with technology in higher education: blended and distance education needs 'joined-up thinking'rather than technological determinism. Open Learning: The Journal of Open, Distance and e-Learning, 29(3), 206-221.

xiii.Kok, A. (2007). ICT Integration into Classrooms: Unpublished literature review

xiv. Kukkonen, J. E., Kärkkäinen, S., Dillon,P., \&Keinonen, T. (2013). The effects of scaffolded simulation-based inquiry learning on fifth-Graders' representations of the Greenhouse effect. International Journal of Science Education. Retrieved SEP. 10, 2012, from http://dx.doi.org/10.1080/09500693.2013.782452

xv. Miller, M. (2009). What the Science of Cognition Tells Us About Instructional Technology. Change, 41(2), 1617. Retrieved November 28, 2009, from Research Library.

xvi. OECS.(2002). Information and Communication Technology (ICT) Learning Outcomes in Mathematics and Language Arts for Lower Secondary School Students in the Eastern Caribbean. OECS Education Reform Unit. Retrieved June 12, 2008, from http://www.oecs.org/oeru/documents/ICT\%20Learning\%20Outcomes\%20Final.pdf

xvii. Oyzon, M. V. L. \& Olmos, O. L. (2010). Students' notes and their relation to comprehension and recall of lecture information. Retrieved fromhttp://journals.upd.edu.ph/index.php/ali/article/view/1752 
xviii. Porter, D., Weaver, A. J., \& Raptis, H. (2012). Assessing students' learning about fundamental concepts of climate change under two different conditions. Environmental Education Research, 18(5), 665686

xix. Şahbaz, N. K. (2012). Evaluation of reading attitudes of 8th grade students in.primary education according to various variables. Educational Research and Reviews, 7(26), $571-576$.

xx. Sanacore, J. (2008). Turning reluctant learners into inspired learners. The Clearing House: A Journal of Educational Strategies, Issues and Ideas, 82(1), 40-44.

xxi. software and information industry association. 2000. Research report on the effectiveness of technology in schools. Executive summary http://www.siia.net/sharedcontent/store le-edtech-sum00.pdf (Accessed 11 December 2002).

xxii. Volman, M. (2005). A variety of roles for a new type of teacherEducational technology and the teaching profession. Teaching and Teacher Education, 21(1), 15-31.

xxiii. Yoloye, E. O. (2015). New technologies for teaching and learning: Challenges for higher learning institutions in developing countries. Information communication technology (ICT) integration to educational curricula: A new direction for Africa, 250. 